\title{
Resistencia microbiana desde una perspectiva metagenómica
}

\author{
Microbial resistance from one metagenomic perspective
}

Título abreviado: Resistencia microbiana y metagenómica

Ospino Bejarano KA¹, Castilla Pérez MG², Sánchez-Mora RM ${ }^{3}$

\section{Resumen}

Objetivo. La finalidad de esta revisión es abarcar la temática relacionada con los genes de resistencia a antibióticos, sus orígenes, reservorios y movimientos en los diferentes hábitats mediante la metagenómica funcional que permite aislar, identificar y analizar estos genes, así como el impacto que tienen en salud pública. Durante los últimos ańos se ha visto un gran avance en la microbiología, una de las grandes limitaciones a las que se venían enfrentado los microbiólogos era no poder acceder a la totalidad de los microorganismos que habitan el planeta. Gracias al desarrollo de diferentes disciplinas como la metagenómica se ha logrado tener el acceso a estos microorganismos. Metodología. La importancia de la metagenómica en la resistencia microbiana radica en que, actualmente, solo el $1 \%$ de los microorganismos que habitan el suelo pueden ser estudiados por técnicas convencionales de microbiología, quedando alrededor del $99 \%$ de estos sin estudiar. Al mitigar este gran inconveniente, la metagenómica permite el estudio de la microbiota del suelo en su totalidad generando nuevo conocimiento e información relevante en diferentes campos científicos. Resultados. Mediante la metagenómica funcional se ha podido determinar que el suelo puede ser un posible reservorio de determinantes de resistencia microbiana, debido a que la microbiota que allí habita contiene en su material genético genes de resistencia a antibióticos que confieren resistencia a un amplio espectro de antibióticos utilizados en terapia humana de forma indiscriminada y además tienen todos los mecanismos de resistencia conocidos, algunos de estos genes son generados por presión selectiva ante diferentes agentes presentes en su medio y otros son genes constitutivos que cumplen con funciones significativas en su hábitat. El gran impacto que tienen estos hallazgos está dado en que pueden representar un posible riesgo en salud pública si se adquieren por los patógenos humanos.

Palabras claves: metagenómica, suelo, genes de resistencia a antibióticos, transferencia horizontal de genes, resistoma.

1. Bacterióloga y Laboratorista Clínico Universidad Colegio Mayor de Cundinamarca. Joven investigadora de Colciencias.

2. Bacterióloga y Laboratorista Clínico Universidad Colegio Mayor de Cundinamarca. Joven investigadora de Colciencias. Docente Universidad

Colegio Mayor de Cundinamarca.

3. Investigadora Grupo Biotecnología y Genética UCMC. Docente Universidad Colegio Mayor de Cundinamarca. 


\begin{abstract}
Objective. The purpose of this review is to cover the issues related to antibiotic resistance genes, their origins, reservoirs and movements in different habitats through functional metagenomics that allows to isolate, identify and analyze these genes, as well as the impact they have on health public. During the last years a great advance in the microbiology has been seen, one of the great limitations to which the microbiologists had been facing was not being able to have access to the totality of the microorganisms that inhabit the planet. Thanks to the development of different disciplines such as metagenomics, access to these microorganisms has been achieved. Method. The importance of metagenomics in microbial resistance lies in the fact that currently only 1 $\%$ of the microorganisms that inhabit the soil can be studied by conventional microbiology techniques, leaving about $99 \%$ of these without studying, the metagenomics by mitigating this great disadvantage allows the study of the soil microbiota in its entirety generating new knowledge and relevant information in different scientific fields. Results. Through functional metagenomics it has been possible to determine that the soil can be a possible reservoir of determinants of microbial resistance, because the microbiota that live there contain in their genetic material antibiotic resistance genes that confer resistance to a broad spectrum of antibiotics used in human therapy indiscriminately and also have all known mechanisms of resistance, some of these genes are generated by selective pressure against different agents present in their environment and others are constitutive genes that fulfill significant functions in their habitat. The great impact of these findings is that they can represent a possible public health risk if they were acquired by human pathogens.
\end{abstract}

Keywords: metagenomics, soil, antibiotic resistance genes, horizontal gene transfer, resistoma.

\section{Introducción}

La metagenómica es el estudio o el análisis genómico y funcional de diversas comunidades microbianas que no son cultivables a nivel de laboratorio; se construyó sobre la base de los avances en la genómica microbiana, amplificación por PCR, clonación y secuenciación de genes altamente conservados como el ARNr $16 \mathrm{~S}$, el nif, el recA, entre otros (1-3). El termino metagenomica se utilizó por primera vez en el año 1998 por los científicos Handelsman Jo y colaboradores, los cuales definieron al metagenoma como el conjunto de genomas de la microbiota del suelo que permite acceder a los genes de las diferentes comunidades microbianas que componen ese ecosistema de forma directa sin necesidad de un cultivo previo (4).
La metagenómica nace por la necesidad de determinar, explorar y analizar las comunidades microbianas de diversos ambientes. Esto permite recuperar nueva diversidad genética, acceder al estudio de rutas metabólicas y comportamiento ecológico de estas comunidades y a acceder a la secuencia de sus genes $(1,2)$.

Un proyecto metagenómico consta de los siguientes pasos: clonación de $\mathrm{ADN}$, construcción de bibliotecas metagenómicas, selección de los clones mediante la detección basada en función o basada en secuencia y por último el análisis de los datos obtenidos $(5,6)$. Los análisis de las secuencias junto con los análisis funcionales proveen una visión del potencial genómico y del papel ecológico de los microorganismos (3). 
Es importante resaltar que el tamizaje de las bibliotecas metagenómicas se realiza basado en función o en secuencia y su uso depende del objetivo del estudio. En el enfoque basado en función, la biblioteca es detectada por la expresión de características fenotípicas, mientras que en el enfoque basado en secuencia la biblioteca es detectada por las secuencias de $\mathrm{ADN}$. Estos dos enfoques han permitido el descubrimiento de nuevas enzimas y antibióticos $(1,2,7)$.

Uno de los ambientes más estudiados mediante metagenómica ha sido el suelo, de hecho, los primeros estudios metagenómicos fueron realizados en este ambiente (4), encontrándose diferentes biomoléculas, enzimas y genes (8). La metagenómica funcional, o también llamada metagenómica basada en función, junto con el implemento de nuevas técnicas y herramientas bioinformáticas, ha permitido la comprensión de los Genes de Resistencia a Antibióticos (GRA), sus orígenes, reservorios y movimientos $(9,10)$.

La resistencia antimicrobiana generada desde el inicio de la era antibiótica se ha dado por el uso excesivo y mal uso de los antibióticos creando la aparición e incremento de microorganismos pató- genos resistentes a todas las clases de antibióticos conocidos (naturales, semisintéticos y sintéticos). Esta situación obstaculiza el tratamiento de enfermedades no solo en humanos sino también en plantas y animales, obligando a descubrir nuevos antibióticos y a comprender los genes que ocasionan esta resistencia, sus orígenes, reservorios y sus movimientos (ecología de los genes de resistencia a antibióticos) para así mismo poder afrontar esta crisis en salud (11-13).

La finalidad de esta revisión es abarcar la temática relacionada con los genes de resistencia a antibióticos, sus orígenes, reservorios y movimientos en los diferentes hábitats y poder visualizar la metagenómica como herramienta útil para aislar, identificar y analizar estos genes que son albergados por microorganismos que habitan los suelos, así como el impacto que tienen en salud pública.

Estudio de genes de resistencia microbiana mediante metagenómica funcional

Para comprender el tema de resistencia microbiana a antibióticos, desde el punto de vista metagenómico, es importante conocer las tres definiciones que existen de resistencia antimicrobiana en la actualidad (figura 1).

Figura 1. Resistencia a antibiótico.

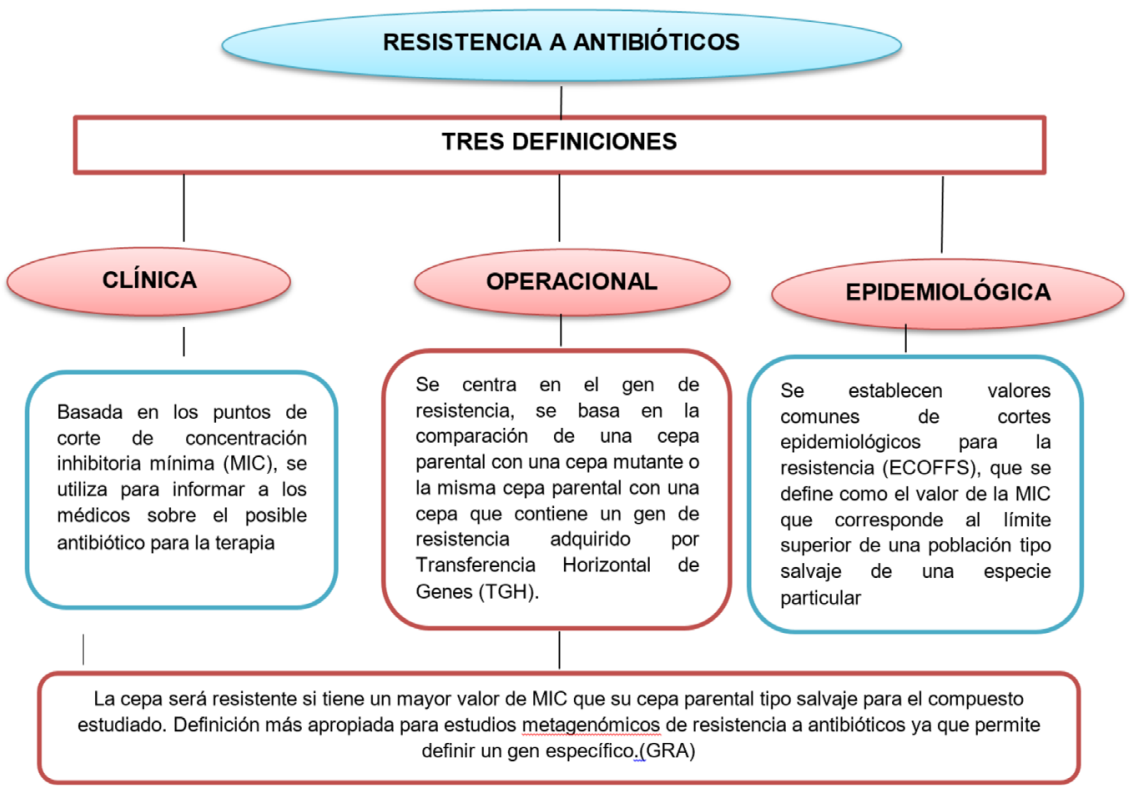

Fuente. Elaborado a partir de Martínez y colaboradores (12). 
La primera, la definición clínica, se basa en los puntos de corte de la concentración mínima inhibitoria (MIC) y se utiliza para informar a los médicos sobre el posible antibiótico de elección para la terapia. Esta definición no es válida para microorganismos que no son patógenos humanos y tampoco para compuestos antimicrobianos que no son utilizados en terapia, ya que en éstos no se han determinado tales puntos de corte. La segunda es la definición epidemiológica en la cual se establecen valores comunes de cortes epidemiológicos para la resistencia (ECOFFS), que se define como el valor de la MIC que corresponde al límite superior de una población tipo salvaje de una especie particular. Los ECOFFS se establecen analizando un gran número de aislados de la misma especie bacteriana para determinar la distribución normal de sus MICs. Se utiliza para cualquier combinación microorganismo-antimicrobiano, incluyendo los biocidas, pero es limitada cuando se desea analizar un único gen o mutación en determinado aislado. La tercera es la definición operacional que se centra en el gen de resistencia, al contrario de las anteriores definiciones que se centran en las especies y se basan en la comparación de una cepa parental con una cepa mutante o la misma cepa parental con una cepa que contiene un gen de resistencia adquirido por Transferencia Horizontal de Genes (TGH). La cepa será resistente si tiene un mayor valor de MIC que su cepa parental tipo salvaje para el compuesto estudiado. La expresión o inactivación de estos genes hacen a un organismo huésped susceptible, de una u otra manera, más resistente a un antibiótico particular. Esta definición es la más apropiada para estudios metagenómicos de resistencia a antibióticos ya que permite a los investigadores definir un gen específico.

En los estudios de resistencia antimicrobiana se utiliza la metagenómica funcional debido a que permite descubrir genes cuya función es difícil de determinar a partir de sólo la secuencia (13-15). Diferentes estudios metagenómicos basados en función han demostrado la presencia de GRA en diferentes ecosistemas, confirmando su ubicuidad en el ambiente, generando así un posible riesgo para la salud humana debido a que pueden ser adquiridos por patógenos humanos $(13,12,16)$.

Uno de los primeros estudios realizados mediante metagenómica en el cual se identificaron GRA en suelo fue el realizado por Riesenfeld y colaboradores en el 2004 (14). Estos científicos identificaron clones que expresaban resistencia a dos tipos de antibióticos, los aminoglucósidos y las tetraciclinas, los GRA responsables de conferir esta característica a los clones diferían de los GRA que se conocían hasta ese entonces, por ello, estos autores propusieron que las bacterias del suelo podrían ser un reservorio de nuevos GRA y que su diversidad genética era mucho mayor a lo que se creía.

De ahí en adelante infinidad de estudios en esta área se han desarrollado y se han identificado compuestos con funciones antibióticas que son producidos por microorganismos que habitan el suelo. Por ejemplo, se han aislado y caracterizado a partir de bibliotecas metagenómicas de $\mathrm{ADN}$ de suelo, antibióticos como la turbomicina A y B (17), de suelos supresores de enfermedad se han hallado clones que contienen una riqueza de loci de biosíntesis de antibióticos, con un consecuente potencial de producción de antibióticos (18). También se han recuperado e identificado enzimas con capacidad biocontroladora y antifúngica como la quitinasa bacteriana, Chil8H8 (19), se han identificado genes que codifican para nuevas moléculas terapéuticas como las policétidos sintasas tipo I y tipo II que contribuyen a la síntesis de los antibióticos eritromicina, epitilona, y rifampicina mediante Streptomyces spp; las péptido sintetasas que contribuyen a la síntesis de antibióticos complejos (1-3).

\section{Genes de resistencia en suelos sin actividad antropogénica}

Se ha demostrado también la presencia de GRA en suelos en ausencia de presión selectiva mediada por actividades antropogénicas, en gran medida esto se debe a que estos suelos contienen bajas concen- 
traciones de compuestos que seleccionan para esa resistencia. Un claro ejemplo son los antibióticos betalactámicos que se encuentran en grandes proporciones en el suelo de forma natural ya que en este habitan una densa población de microorganismos que los produce, esto podría explicar la razón de porqué se ha encontrado GRA en suelos sin actividad antropogénica.

En el 2009 Allen y otros realizaron un estudio metagenómico en un suelo de Alaska virgen, en el cual identificaron GRA $\beta$-lactámicos que codifican tanto para $\beta$-lactamasas divergentes como para la primera $\beta$-lactamasa bifuncional que posiblemente es una fusión natural entre dos enzimas de longitud completa, confiriéndole una ventaja selectiva en un ambiente clínico a los organismos patógenos que puedan albergar estos genes. Estos hallazgos comprueban que los determinantes de resistencia a $\beta$-lactámicos se encuentran en ecosistemas con ausencia de presión selectiva del uso moderno de antibióticos, debido a que son suelos remotos sin ningún tipo de actividad antropogénica (13).

\section{Genes de resistencia en suelos con actividad antropogénica}

Por otro lado, se ha demostrado que el uso de antibióticos en la agricultura contribuye a la propagación de genes de resistencia. Los mecanismos por los cuales estas prácticas agrícolas influyen en la resistencia son desconocidos y también su impacto en el resistoma y microbioma del suelo. En el estudio realizado por Forsberg y otros en el 2014 se descubrieron GRA que representan todos los principales mecanismos de resistencia, además demostraron que los distintos tipos de suelo, tanto suelos agrícolas como de pastizales albergan distintos resistomas debido a la adición de fertilizantes nitrogenados que influyen fuertemente en su contenido siendo las betalactamasas empobrecidas y los trasportadores de membranas enriquecidos y favoreciendo organismos particulares como los copiotrofos que causan cambios en la abundancia bacteriana que a su vez probablemente afectará la composición del resistoma.

El suelo contiene una enorme diversidad de GRA, cuyos genotipos preexistentes pueden ser favorecidos por el incremento a la exposición a antibióticos y no por la adquisición de nuevos GRA. Se puede inferir que el principal determinante del contenido del resistoma del suelo es la filogenia. Al cambiar la diversidad y el tipo bacteriano a través de los suelos, así mismo, lo hacen sus GRA asociados, resultando en resistomas que pueden responder a las modulaciones antropogenicas como lo son los fertilizantes nitrogenados y que no poseen propiedades relacionadas a los antibióticos (20).

Estudios como el de Nikolina y otros en el 2014 demostraron que los suelos tratados con estiércol de vacas que no han recibido tratamiento antibiótico aumentaron la cantidad de GRA betalactámicos existentes en ese suelo. Los GRA son abundantes en estiércol de animales que no tienen historia de tratamiento antibiótico debido a la presencia natural de estas bacterias intrínsecamente resistentes a antibióticos que habitan el tracto gastrointestinal de los animales (21).

Los GRA del resistoma del suelo pueden entrar a la cadena alimenticia vía cultivos contaminados o aguas subterráneas y tener potenciales consecuencias en salud humana si son transferidos a patógenos (21).

\section{Transferencia horizontal de genes entre bacterias del suelo y patógenos clínicos}

Los GRA presentes en un suelo, con o sin actividad antropogénica, pueden ser adquiridos por los patógenos humanos mediante diferentes vías. Una de las vías propuestas en esta adquisición es la transferencia horizontal de genes (THG), un estudio que lo respalda es el realizado por Forsberg y otros en el 2012 quienes encontraron que los GRA de las bacterias del suelo que estudiaron tienen una similitud 
del $100 \%$ con los GRA de los diversos patógenos humanos incluyendo secuencias de movilización que sugieren como mecanismo de diseminación la THG (9).

En la figura 2 se muestra que cuatro de los contigs ensamblados (AB95_GE_3, AB95_CH_13, AB95_TE_2, AB95_PI_68) son más del $99 \%$ idénticos a un gran espacio de secuencia encontrado en numerosos patógenos que contienen una alta densidad de GRA y que es flanqueado por múlti- ples elementos móviles. Los aislados que albergan los GRA están estrechamente relacionado con Pseudomonas sp K94.23 y con Ochrobactrum anthropi; microorganismos que predominan en entornos ambientales y están poco vinculados a causar infecciones en humanos, y son altamente divergentes a los patógenos humanos. Sin embargo, sus GRA presentan el $100 \%$ de identidad con los GRA de patógenos confirmando que estos genes se mueven entre especies vía THG (9).

Figura 2. Comparación de cuatro contigs de resistencia ensamblados (AB95_GE_3, AB95_CH_13, AB95_TE_2, AB95_PI_68) y derivados de una colección de cultivos con cinco aislados de patógenos humanos. Se muestran los diferentes GRA que comparten.

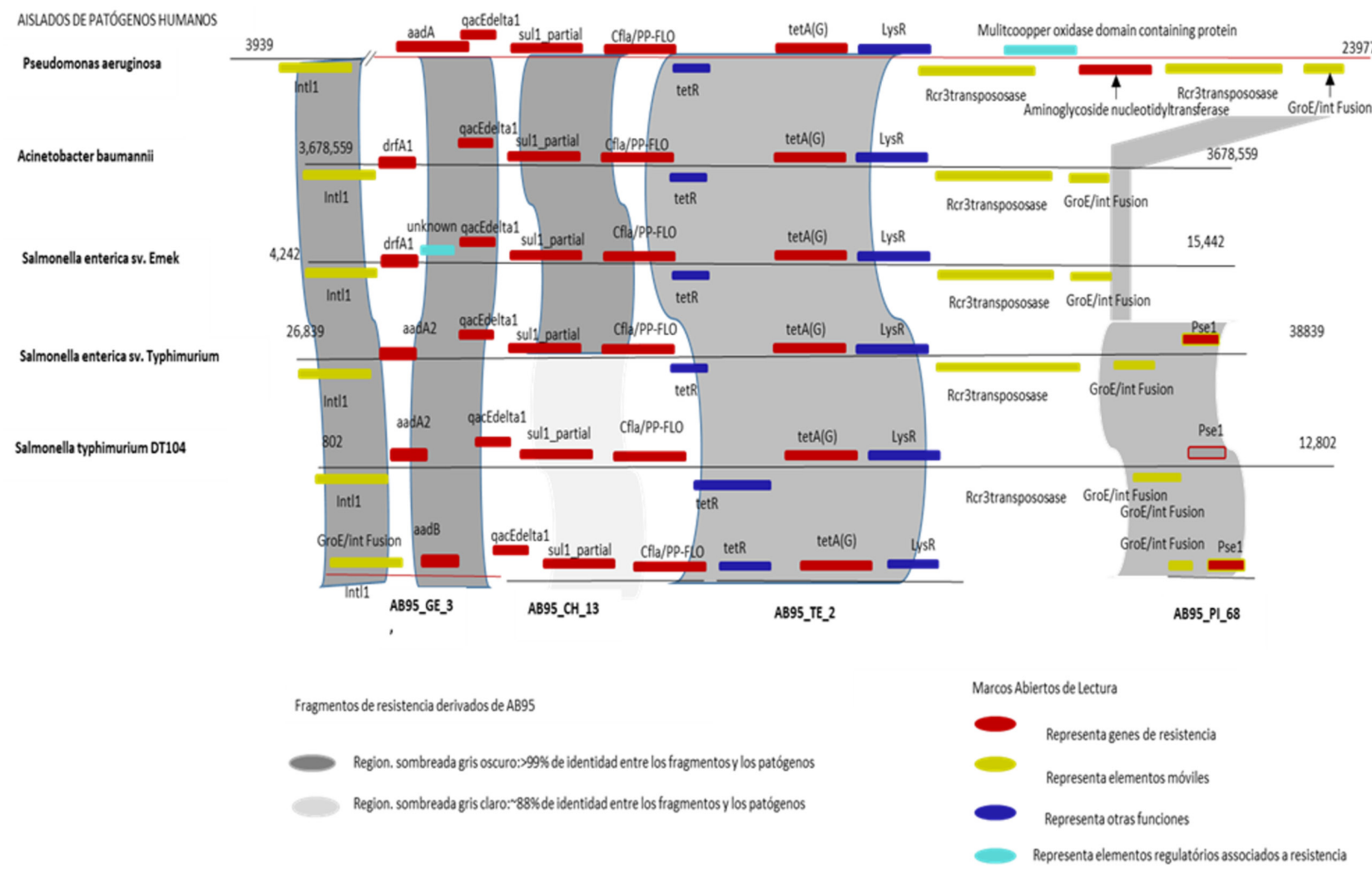

Fuente. Elaborado a partir de Forsberg y otros (9).

Ahora bien, se sabe que la resistencia está dada por GRA que se pueden definir como GRA ecológicos o GRA operacionales (figura 3). Los GRA ecológicos han evolucionado en la naturaleza con el objetivo de proteger a un organismo del efecto inhibitorio de un antimicrobiano producido por otro organismo. La fuerte presión selectiva ha llevado a un cambio en la función ecológica de estos genes que son adquiridos por patógenos mediante THG desde que inició el uso de antibióticos por los humanos (12). 
Figura 3. Definiciones de genes de resistencia microbiana GRA ecológicos / operacionales.

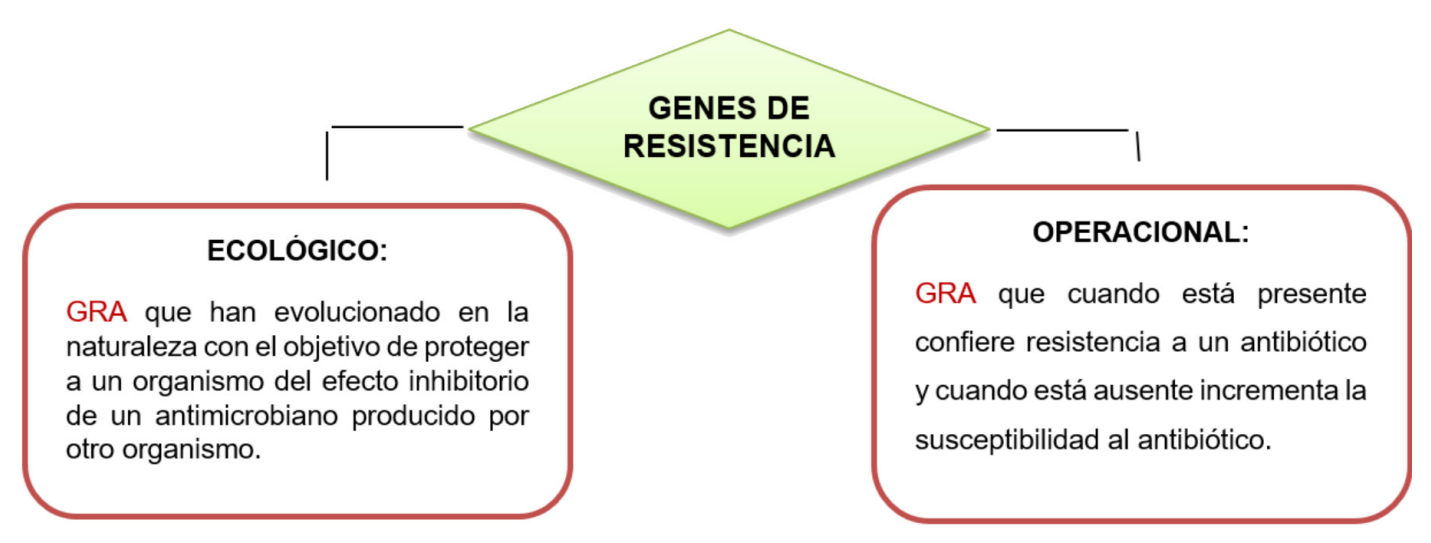

Fuente. Elaborado a partir de Martínez y colaboradores (12).

No todos los genes que confieren a un organismo el fenotipo de resistencia son GRA. Por ejemplo, existen genes que codifican para proteínas detoxificadoras que tienen como función detoxificar el ambiente de éstos compuestos antibióticos más no resistir su acción; o las bombas eflujo cuya función original es resistir las sales biliares y no los antibióticos utilizados en terapia humana; también las $\beta$-lactamasas tipo $A m p C$ en las enterobacterias que contribuyen al mantenimiento de la morfología normal de E. coli (12).

Los GRA operacionales son aquellos que cuando están presente confiere resistencia a un antibiótico y cuando está ausente incrementa la susceptibilidad al antibiótico. Algunos genes son identificados como genes de resistencia (acrAB y ampC en E. coli, mexAB en Pseudomonas aeruginosa, aac ( $\left.6^{\prime}\right)-I i$ en Enterococcus faecium y blaOXY en Klebsiella oxytoca) que pertenecen al genoma del núcleo de estas especies y son responsables por naturaleza, de fenotipos de resistencia intrínsecos. Sin embargo, estos genes no contribuyen al grupo común de genes de resistencia que son capaces de circular entre bacterias. Por tal razón, los análisis metagenómicos deben ser capaces de diferenciar los genes del núcleo de los genes que son capturados por elementos móviles genéticos para, así mismo, conocer su riesgo real en salud pública (12).

\section{Riesgos asociados con la presencia de un potencial GRA en un ecosistema dado}

Los GRA identificados mediante metagenómica se clasifican en categorías según los riesgos que puedan presentar en salud pública, es decir, el riesgo de que sean adquiridos y confieran resistencia a patógenos humanos. Los niveles de riesgo llamados REScon (condición de la disposición de resistencia), se clasifican desde el riesgo más alto REScon 1 hasta el riesgo más bajo REScon 7 (22).

- REScon 1: son los genes de resistencia que contribuyen al fracaso de tratamientos con antibióticos, estos genes residen en elementos genéticos móviles alojados en patógenos humanos. Actualmente son los causantes de problemas hospitalarios, se expresan de forma heteróloga en diferentes huéspedes y pueden ser silenciado en un huésped especifico $(22,23)$.

- REScon 2: son genes de resistencia nuevos que inactivan los antibióticos utilizados en terapia humana y están localizados en elementos genéticos móviles en bacterias no patógenas. La captura y la selección de un gen de resistencia nuevo, por un elemento genético móvil, podría 
ser el primero paso para su posterior adquisición en un patógeno humano (22).

- $\quad$ REScon 3: son los genes que confieren resistencia a los antibióticos en fase de desarrollo I, II o III, a los que no son ampliamente usados y a los antibióticos viejos que casi no se usan (22).

- $\quad$ RESCon 4: son los genes que confieren resistencia a un agente microbiano clínico en uso, por un mecanismo desconocido, pero la resistencia a este agente ocurre en patógenos humanos por otro mecanismo $(23,22)$.

- $\quad$ REScon 5: son genes que pertenecen a una familia de genes conocida y pueden inactivar antibióticos específicos, presentando un perfil de alta similitud al sustrato de antibióticos de los genes de resistencia conocidos.

- REScon 6: son los genes que confieren resistencia y están presenten en elementos genéticos móviles, la predicción de esta resistencia se basa en la alta similitud de sus secuencias con genes de resistencia caracterizados funcionalmente y por su presencia documentada en elementos genéticos móviles (22).

- $\quad$ REScon 7: son los genes que adjudican resistencia sin ninguna relación conocida con elementos genéticos móviles. Se cree que confieren resistencia a los antibióticos, ya que comparten un cierto grado de identidad con los genes de resistencia funcionalmente caracterizados, sin que la información esté disponible (22).

\section{Discusión}

La metagenómica ha abierto las perspectivas al estudio de las comunidades microbianas en diferentes ambientes, y ha permitido acceder al conjunto de genomas de dichas comunidades. Lo anterior es muy importante en la comunidad científica debido a los grandes aportes que se han generado; creando una nueva visión en la microbiología. Mediante la metagenómica se ha podido estudiar a profundidad uno de los ecosistemas más complejos, el suelo, que alberga comunidades microbianas de mucho interés en la academia, industria, salud y demás. El acceso al resistoma del suelo ha conllevado a importantes hallazgos sobre la resistencia microbiana que es tan importante en salud pública, se ha logrado llegar a un entendimiento de la ecología de los genes de resistencia a antibióticos y todos los factores que influyen en esta.

Se sabe que el suelo es un reservorio de nuevos genes de resistencia antimicrobianos, estudios como el de D'Costa y colaboradores en el 2006 (24) permitieron encontrar determinantes de resistencia a múltiples antibióticos en Actinomicetos del suelo y respaldaron la idea de que el suelo es un reservorio de GRA. Por otro lado, Donato y colaboradores en el 2010 (15) identificaron enzimas bifuncionales en suelo expuestos a actividad antropogénica creando formas de albergar microorganismos que desarrollen resistencia a diferentes antibióticos.

Su y colaboradores en el 2014 (24) también identificaron y caracterizaron GRA en suelos agrícolas y evaluaron el impacto de las prácticas agrícolas, confirmaron que éstas aumentan la diversidad de genes de resistencia a antibióticos en las bacterias del suelo y que pueden conducir a la propagación de resistencia a bacterias del suelo (26).

D'Costa y colaboradores en el 2011 demostraron que la resistencia a antibióticos es antigua y es un fenómeno natural anterior a la presión selectiva moderna del uso clínico de los antibióticos (11). Por lo tanto, los genes de resistencia a antibióticos existen y existieron mucho antes del comienzo de la era antibiótica. La resistencia no es un fenómeno que esté principalmente asociado con su real presión selectiva (típico de la moderna era antibiótica), pero es una característica que es inherente a los microorganismos en la naturaleza (27-32). 


\section{Conclusiones}

La resistencia microbiana va más allá del entorno clínico con el que se suele relacionar, los diferentes ecosistemas están en estrecha relación con la ecología de los genes de resistencia a antibióticos, sus orígenes, reservorios y movimientos. Uno de los ambientes más estudiados ha sido el suelo, gracias a la metagenómica que ha permitido el acceso al resistoma de éste, y que ha permitido dilucidar varias incógnitas respecto a la ecología de los GRA. A pesar de que se ha avanzado mucho en el tema, aún falta conocer con exactitud los riesgos reales que representan estos genes y la influencia o impacto que puede tener la actividad del ser humano en los diferentes ecosistemas, no solamente el suelo.

\section{Referencias}

1. Handelsman J. Metagenomics: Application of Genomics to Uncultured Microorganisms. Mol. Biol. Rev. 2004; 68(4): 669-669. https://doi.org/10.1128/MBR.68.4.669685.2004

2. Schloss PD, Handelsman J. Biotechnological prospects from metagenomics. Current Opinion in Biotechnology. 2003. https://doi.org/10.1016/S0958-1669(03)00067-3

3. Streit WR, Schmitz RA. Metagenomics-The key to the uncultured microbes. Current Opinion in Microbiology. 2004; 7(5): 492-498. https://doi.org/10.1016/j.mib.2004.08.002

4. Handelsman J, Rondon MR, Brady SF, Clardy J, Goodman RM. Molecular biological access to the chemistry of unknown soil microbes: a new frontier for natural products. Chemistry \& Biology. 1998; 5(10): R245-R249. https:// doi.org/10.1016/S1074-5521(98)90108-9

5. Simon C, Daniel, R. Metagenomic analyses: Past and future trends. Applied and Environmental Microbiology. 2011; 77(4): 1153-1161. https://doi.org/10.1128/AEM.02345-10

6. Chen K, Pachter L. Bioinformatics for whole-genome shotgun sequencing of microbial communities. PLoS Computational Biology. 2005; 1(2): 0106-0112. https://doi. org/10.1371/journal.pcbi.0010024

7. Rondon MR, August PR, Bettermann AD, Brady SF, Grossman TH, Liles MR, Goodman RM. Cloning the soil metagenome: A strategy for accessing the genetic and functional diversity of uncultured microorganisms. Applied and Environmental Microbiology. 2000. https://doi.org/10.1128/ AEM.66.6.2541-2547.2000

8. Daniel R. The soil metagenome - A rich resource for the discovery of novel natural products. Current Opinion in Biotechnology. 2004. 15(3): 199-204. https://doi.org/10.1016/j. copbio.2004.04.005

9. Forsberg KJ, Reyes A, Wang B, Selleck EM, Sommer MOA, Dantas G. The shared antibiotic resistome of soil bacteria and human pathogens. Science. 2012; 337(6098): $1107-$ 1111. https://doi.org/10.1126/science. 1220761

10. Gibson MK, Forsberg KJ, Dantas G. Improved annotation of antibiotic resistance determinants reveals microbial resistomes cluster by ecology. ISME Journal. 2015; 9(1): $207-$ 216. https://doi.org/10.1038/ismej.2014.106

11. Dcosta, VM, King CE, Kalan L, Morar M, Sung WWL, Schwarz C, Wright GD. Antibiotic resistance is ancient. Nature. 2011; 477(7365): 457-461. https://doi.org/10.1038/ nature 10388

12. Martínez JL, Coque TM, Baquero F. The influence of antibiotic resistance on human and animal health and welfare; 2014. https://doi.org/10.1038/nrmicro3399

13. Allen HK, Moe LA, Rodbumrer J, Gaarder A, Handelsman $\mathrm{J}$. Functional metagenomics reveals diverse b-lactamases in a remote Alaskan soil. The ISME Journal. 2009; 386, $243-$ 251. https://doi.org/10.1038/ismej.2008.86

14. Riesenfeld CS, Goodman RM, Handelsman J. Uncultured soil bacteria are a reservoir of new antibiotic resistance 9 genes. Environmental Microbiology. 2004. https://doi.or$\mathrm{g} / 10.1111 / \mathrm{j} .1462-2920.2004 .00664 . \mathrm{x}$

15. Donato JJ, Moe LA, Converse BJ, Smart KD, Berklein EC, McManus PS, Handelsman J. Metagenomic analysis of apple orchard soil reveals antibiotic resistance genes encoding predicted bifunctional proteins. Applied and Environmental Microbiology. 2010; 76(13), 4396-4401. https://doi. org/10.1128/AEM.01763-09

16. Rojas FAR, Ordoñez PSB, Sanchez MRM. Detección de Chlamydia trachomatis en hombres que tienen sexo con hombres en Bogotá: un estudio piloto. NOVA. 2016: 14(26): 17-27.

17. Gillespie ES, Brady A, Bettermann N, Cianciotto R, Mark MR, Clardy R, Goodman AJ. (2002). Isolation of antibiotic Turbomycin A and Turbomycin B from a metagenomic library. Applied and Environmental Microbiology. 2002; 68(9): 4301-4306. https://doi.org/10.1128/ AEM.68.9.4301

18. Van Elsas JD, Speksnijder AJ, Van Overbeek LS. A procedure for the metagenomics exploration of disease-suppressive soils. Journal of Microbiological Methods. 2008; 75(3): 515-522. https://doi.org/10.1016/j.mimet.2008.08.004

19. Hjort K, Presti I, Elväng A, Marinelli F, Sjöling S. Bacterial chitinase with phytopathogen control capacity from suppressive soil revealed by functional metagenomics. Applied Microbiology and Biotechnology. 2014; 98(6): 2819-2828. https://doi.org/10.1007/s00253-013-5287-x

20. Forsberg KJ, Patel S, Gibson MK, Lauber CL, Knight R, Fierer N, Dantas G. Bacterial phylogeny structures soil resistomes across habitats. Nature. 2014; 509(7502): 612-6. https://doi.org/10.1038/nature13377 
21. Udikovic-Kolic N, Wichmann F, Broderick NA, Handelsman J. Bloom of resident antibiotic-resistant bacteria in soil following manure fertilization. Proceedings of the National Academy of Sciences. 2014; 111(42): 15202-15207. https:// doi.org/10.1073/pnas.140983611

22. Martínez JL, Coque TM, Baquero F. What is a resistance gene? Ranking risk in resistomes. Nat Rev Microbiol. 2015; 13(2):116-23. https://doi: 10.1038/nrmicro3399. Epub 2014 Dec 15.

23. Jutinico SA, Garzón JM, Chacón JM, Gómez M, Sanchez MRM Cultivo de la línea celular HEp-2: doblaje poblacional y coloración con Giemsa. Perspectivas para el estudio de la infección con Chlamydia trachomatis. NOVA; 2013; $11(20)$.

24. D'Costa VM, McGrann KM, Hughes DW, Wright GD. Sampling the antibiotic resistome.Science. 2006; Jan 20;311(5759):374-7.

25. Qiang J. Wei B, Yan C, Qiao M, Guan Y. Functional metagenomic characterization of antibiotic resistance genes in agricultural soils from China. Environment International. 2014; 65: 9-15. https://doi.org/10.1016/j.envint.2013.12.010

26. Su JQ, Wei B, Xu CY, Qiao M, Zhu YG. Functional metagenomic characterization of antibiotic resistance genes in agricultural soils from China. Environment international. 2014; 65: 9-15.

27. Kozhevin PA, Vinogradova KA, Bulgakova VG. The Soil Antibiotic Resistome. 2013; 68 (2): 53-54. https://doi. org/10.3103/S014768741302004X

28. Pinilla B Gladys, Chavarro P Bibiana, Moreno A Natalia, Navarrete O Jeannette, Muñoz M Liliana. Determinación de los genes, 16S ADNr, polA, y TpN47, en la detección de Treponema pallidum subsp. pallidum para el diagnóstico de sífilis congénita. Nova. 2015; 13 ( 24 ): 17-25.

29. Corrales Lucia Constanza, Antolinez Romero Diana Marcela, Bohórquez Macías Johanna Azucena, Corredor Vargas Aura Marcela. Bacterias anaerobias: procesos que realizan y contribuyen a la sostenibilidad de la vida en el planeta. Nova. 2015; $13(24)$ ) 55-81.

30. Carrero Sandra Helena Suescún, HerediaMontoya Dina Paola, Bolaños Yoryany Mulato, Medellín Martín Orlando Pulido. Seroprevalencia de infección por Leptospira y factores de riesgo en estudiantes de una universidad de Colombia. Nova. 2017; $15(27$ ): 131-138.

31. Zuluaga Martha, Robledo Sebastian, Osorio-Zuluaga German A, Yathe Laura, Gonzalez Diana, Taborda Gonzalo. Metabolomics and pesticides: systematic literature review using graph theory for analysis of references. Nova. 2016; 14( 25 ): 121-138

32. Ávila de Navia Sara Lilia, Estupiñán-Torres Sandra Mónica, Díaz González Liliana. Calidad bacteriológica del agua Vereda El Charco, San Miguel de Sema, Boyacá- Colombia. Nova. 2016; 14 ( 25 ): 139-145. 